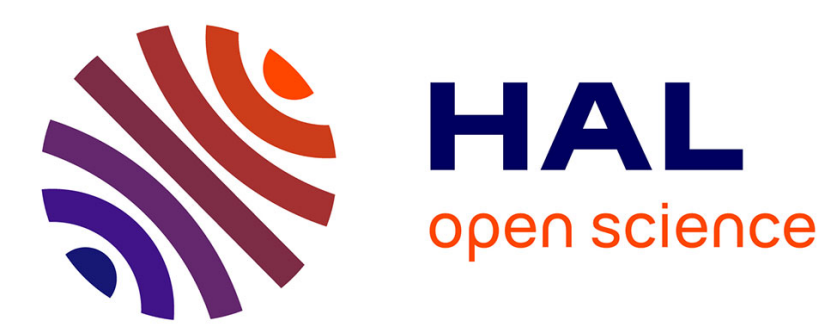

\title{
Analysis of pre-crash characteristics of passenger car to cyclist accidents for the development of Advanced Drivers Assistance Systems
}

François Char, Thierry Serre

\section{- To cite this version:}

François Char, Thierry Serre. Analysis of pre-crash characteristics of passenger car to cyclist accidents for the development of Advanced Drivers Assistance Systems. Accident Analysis \& Prevention, 2020, 136, 12p. 10.1016/j.aap.2019.105408 . hal-02483327

\section{HAL Id: hal-02483327 \\ https://hal.science/hal-02483327}

Submitted on 18 Feb 2020

HAL is a multi-disciplinary open access archive for the deposit and dissemination of scientific research documents, whether they are published or not. The documents may come from teaching and research institutions in France or abroad, or from public or private research centers.
L'archive ouverte pluridisciplinaire HAL, est destinée au dépôt et à la diffusion de documents scientifiques de niveau recherche, publiés ou non, émanant des établissements d'enseignement et de recherche français ou étrangers, des laboratoires publics ou privés. 
Analysis of pre-crash characteristics of passenger car to cyclist accidents for the development of Advanced Drivers Assistance Systems

\section{François CHAR}

IFSTTAR-LMA

Chemin de la Croix Blanche, 13300 Salon de Provence, France Aix-Marseille University

ED 463 Sciences du Mouvement Humain

163 avenue de Luminy, Marseille, France

francois.char@ifsttar.fr

Thierry SERRE*

IFSTTAR-LMA

Chemin de la Croix Blanche, 13300 Salon de Provence, France thierry.serre@ifsttar.fr

(tel: +33490568653 ; fax: + 334905686 18) 
* Corresponding author

Abstract

The purpose of this study was to analyze car-to-cyclist accidents to determine the challenges for an active safety system on car to avoid accidents. Based on 2261 car-to-cyclist accidents provided by in-depth accident databases, accidents are analyzed more specifically from kinematic reconstructions. The main accident scenarios are determined: crossing nearside, crossing farside, longitudinal, turning (right and left) and others. Proportion of brakes activation by the drivers before the impact was also given for those scenarios. The relative positions of the cyclists to the vehicle are analyzed from few seconds before the impact until the crash. It is observed that one second before the impact most of the cyclists were at a lateral distance smaller than $5 \mathrm{~m}$ to the center line of the car and less than $20 \mathrm{~m}$ ahead of car front. Finally, the possible detection of the cyclist by implemented sensors in the vehicle and the possible triggering of an active safety system like an Automatic Emergency Braking or a Forward Collision Warning are studied. Required detection sensors parameters, such as Field Of View (FOV) and the detection range, were analyzed relatively to the scenario's characteristics, e.g. remaining time after cyclist appearance and before the collision, differences between scenario types. Different sensor FOVs and detection ranges were analyzed to determine their possible rates of cyclist detection. The study concluded that a FOV of $60^{\circ}$ and a range of $35 \mathrm{~m}$ would detect most of the cyclists in car-to-cyclist accident scenarios. It was also concluded that in about $80 \%$ of cases, the last time to trigger brake $\left(\mathrm{t}_{\mathrm{LTTB}}\right)$, i.e. the last moment to brake in order to avoid the accident based on physical and comfort braking limitations by the car, was $1 \mathrm{~s}$ before the collision. It was also calculated that with a FOV of $60^{\circ}, 51 \%$ of cyclists could be detected up to $4 \mathrm{~s}$ before $\mathrm{t}_{\mathrm{LTTB}}$, and $72 \%$ up to $1 \mathrm{~s}$ before

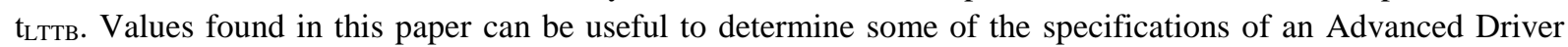
Assistance System (ADAS), e.g. detection sensor coverages, available time to trigger an autonomous emergency braking or forward collision warning device. Those values are given for general ADAS sensors specification but also per scenario in the case of sensors that can adapt to a specific scenario.

Keywords: ADAS, Autonomous Braking, Collision Warning, Cyclist, Field Of View, range, Safety performance, Accident reconstruction

\section{Introduction}

It has been estimated that every year around 1.2 million people in the world die due to accidents on the road (WHO 2015). From the previous stated figure, it has also been found that pedestrians, cyclists and motorcyclists account for $49 \%$ of all the road traffic deaths (WHO 2015). Car manufactures as well as consumer organizations are contributing to the reduction of these type of fatalities by establishing new safety requirements and implementing new active safety systems on vehicles (Euro NCAP, 2018), which support drivers in avoiding or mitigating collisions with vulnerable road users (VRUs). Examples of these active safety systems are the Automatic Emergency Braking (AEB), which is able to trigger an autonomous braking in case of an imminent crash, and the Forward Collision Warning (FCW), which triggers a warning to the driver in the event of a possible collision with a VRU. The European New Car Assessment Program (Euro NCAP) is a safety performance assessment program focused in testing new safety systems to ensure high levels of performance (Euro NCAP, 2017 and 2018). In 2018, Euro NCAP presented their first protocol to test safety systems focused in car-to-cyclist scenarios (Euro NCAP, 2018). The development of these safety systems as well as the test scenarios and safety requirements are the results of many research projects focused on analyzing car-to-cyclist accidents.

Several European research projects (e.g. AsPeCSS, CATS or PROSPECT) have focused in analyzing the accident configuration of the most common car-to-cyclist accident scenarios. The results of these projects has helped in developing better active safety systems as well as developing testing scenarios for assessing pedestrian or cyclist active safety systems. Schaller et al. (2012) used scenarios to develop test procedures for pedestrian safety systems based on GIDAS database analysis of vFFS Group. They found that crossing and turning scenarios represented up to $85 \%$ of the accident scenarios. Rodarius et al. (2014) (AsPeCSS) analyzed the difference between pedestrian and cyclist accidents and proposed 4 tests scenarios for cyclist active safety systems. They proposed 1 crossing, 1 longitudinal, 1 turning left and 1 turning right scenarios. Uittenbogaard et al. (2016a, b) (CATS) analyzed car-tocyclist accidents to define accident scenarios for test protocol. They extracted 2 crossing, 2 longitudinal and 1 turning scenarios. Stoll et al. (2016) (PROSPECT) also defined test cases to validate active safety system performances which were similar to others previous works. By studying the moments before accidents occurred it is possible to determine the characteristics of active safety devices in terms of detection and trigger timing for passenger cars. The present paper aims at analyzing accident characteristics a few seconds before the crash. 
An estimation of effectiveness of Forward Collision Warning (FCW), Automatic Emergency Braking (AEB), lane departure warning or automatic cruise control was determined by several studies (Hamdane et al. 2015; Høye et al. 2015; Coelingh et al. 2010; Forkenbrock and O'Harra 2009). The effect estimation is given in terms of killed or seriously injured people that can be avoided with these systems. According to these studies, from 9 to $16 \%$ VRU could be saved (Høye et al. 2015) and in terms of impact speed reduction up to $35 \mathrm{~km} / \mathrm{h}$ could be gained (Coelingh et al. 2010). If the detection range and FOV of these safety systems increased, higher number of VRUs could be saved as well as higher speed reductions could be obtained.

One of the objectives of this study is to determine the critical time to detect the cyclist and to trigger an action from an active safety device, action that potentially may avoid or mitigate the consequences.

\section{Materials and methods}

\subsection{Accident data}

Crashes data used in this study come from 2 in-depth accident databases, one from Germany and one from France.

The French accident cases were extracted from the "Etudes Détaillées d'Accidents (EDA)" crash database of IFSTTAR/LMA performed in the surrounding of Salon-de-Provence (Ferrandez et al. 1995).

Each accident is investigated by a multidisciplinary team composed of a psychologist and a technician directly on the accident scene in real time at the same time of rescue team intervention. As much evidences as possible are gathered on the scene about involved vehicles and the environment, like vehicles final position, impact of vehicles (deformation, location of impact), marks left on the road (tyres, fluids, debris, etc.), weather and visibility conditions. Drivers statements, witnesses and injuries record based on medical reports are also collected. With those data, hypothesis of the accident mechanisms are made: trajectories of the vehicle and the cyclist, travelling speed, emergency manoeuver, etc. Then the scenario which has the best correlation with all the indications produced by the in-depth analysis is chosen.

The database from Germany is Pre-Crash-Matrix (PCM 160818_GIDAS _PCM_4.0_2016_1). In a similar way, the German methodology is described in (GIDAS 2016). GIDAS accidents are collected in the areas of Hanover and Dresden. Data concerning the car, the environment and the participants are collected like information relative to the condition of the cars and to the collision partner, the deformation, the general setting of the cars, the condition of safety systems and their function. The environment data are gathered in order to have the geometry of the street, the street's condition or traffic controls. Finally, data about the participants are collected like age, gender, information about driving experience, known disease, stress factors. An interview helps to get information about the progress of the accident from the participants' point of view. Additionally, data about injuries can be obtained to analyze long-term consequences.

\subsection{Accidents selection criteria and clustering}

In this study only accident cases involving one passenger car and one cyclist were considered. 30 cyclist accident cases were extracted from EDA and 2231 from the GIDAS-PCM.

All those accidents were clustered into different scenarios based on the trajectories of the car and cyclist. The literature review reported different ways to cluster the cases depending on the view point. As example, Kuehn et al. (2015) scenarios were based on cyclists' provenance, whereas CATS (Uittenbogaard et al. 2016a) and AsPeCSS project (Rodarius et al. 2014) chose to consider the trajectory of the passenger car as the main criterion. The latest was also chosen for this study to have the point of view from a car active safety device. The choice to select the 5 scenarios below was motivated by the fact that those scenarios are common scenarios that can be found in the literature. Thus, it appeared obvious to keep them.

- Crossing Nearside scenario (CN): the vehicle drives straight and a cyclist crosses from the closest side of the road (On a 1 way road, a cyclist crossing from the left or the right is also considered as a $\mathrm{CN}$ ).

- Crossing Farside scenario (CF): the vehicle drove straight and a cyclist crossed at least one lane of road before being hit by the vehicle.

- Longitudinal scenario (L): the vehicle and the cyclist both travelled in the same direction on the road, and the car hits the cyclist in the rear during the travel or laterally during an overtaking manoeuver. 
- Turning Left (TL) or Turning Right scenario (TR): the vehicle was turning left or right at an intersection and hits a cyclist whatever the trajectory of the cyclist. Situations where the vehicle was outside an intersection were excluded from this cluster.

Cases where a vehicle followed a curve to the right (or to the left) and a cyclist crossed the road were clustered either in $\mathrm{CN}$ or CF scenario. Cases where a vehicle was in a curve and encountered a cyclist travelling in the same direction were clustered in the L scenario.

- Other scenarios: all accidents that could not be clustered in any of above scenarios.

\subsection{Accidents reconstruction}

In order to describe the pre-crash phase of the accident, a kinematic reconstruction was performed on the French accident cases investigated by IFSTTAR-LMA based on Lechner and Ferrandez (1990) methodology. At first the approximate trajectories of the vehicle and the cyclist were extracted and drawn in a reduced scale map using their initial and final positions. Objects in the scene that could occlude the cyclist were also added to the scene when the information was available. Then a temporal reconstruction was performed based on information like involved displacement speed, manoeuver (steering manoeuver or braking). During this temporal reconstruction, some assumptions were made:

- The vehicle and the cyclist speeds were constant if there was no brake activation. After brake activation, a constant deceleration speed was considered until the impact.

- A constant deceleration was considered from initial brake trigger.

- The deceleration value was adjusted depending on road conditions, weather and brake conditions defined by experts.

- The cyclist displacement speed was estimated from its path to the point of collision with the car. Car deformation zones and participants' speed declaration may add further information to define cyclist's speed.

GIDAS accident pre-crash phase kinematics and information, readily available in GIDAS-PCM database, were used for this study in addition to French cases. The methodology to create PCM cases is defined in Schubert et al. (2012).

2.4 Pre-crash phase parameters analysis

Several parameters were extracted for each accident case:

- Location of the cyclist relatively to the vehicle at different times (in second) to collision (TTC),

- Relative angular position and distance of the cyclist to the car

- $\quad$ Last Time To Brake (LTTB) calculated using equation 1. The LTTB is a measure in distance which corresponds to the last moment to trigger the brakes in order to avoid the collision. LTTB is calculated according to equation (1):

$$
\operatorname{LTTB}=\frac{V^{2}}{2 *|a|}(\text { eq. 1) [in meter] }
$$

Where $V$ is the vehicle traveling speed $(\mathrm{m} / \mathrm{s}), a$ is the deceleration $\left(\mathrm{m} / \mathrm{s}^{2}\right)$ that depends on road conditions. This formula is similar to the one used in Hamdane et al. (2015). It is also close to the one that can be found in Violette and Le Bec (2016) where the coefficient value estimation takes into account the transient state. In the current paper, an ideal braking model is considered excluding transient state and an average deceleration value of $-8 \mathrm{~m} / \mathrm{s}^{2}$ has been taken. This value corresponds to ideal conditions like dry surface, efficient braking system, etc., and corresponds to an average deceleration as found in Brach and Brach (2005), Byatt and Watts (1981) and Lechner and Ferrandez (1990). A comparison of this ideal model has been performed with a more realistic model as it can be found in Saadé et al. (2019) and in Zhao et al. (2019). In this more realistic model, the value $a$ linearly increases from the trigger until it reaches the maximum deceleration of $-8 \mathrm{~m} / \mathrm{s}^{2}$ and the time needed to reach the maximum value is set to $0.15 \mathrm{~s}$. As the deceleration $a$ value varies, the speed also varies accordingly to $a$. So, the LTTB distance travel is computed using (eq.1) according to the variation of $a$ and the time step (0.01s). Distances are computed until the condition that the speed is equal to zero. The result of this comparison can be found in part 3.2. The analysis of above accident parameters allowed defining required sensor detection range, FOV and triggering time for an active safety device. The sensor was modelled at the geometrical center of the vehicle. Braking was the only avoidance manoeuver considered in this study. Figure 1 illustrates the representation of the FOV and the range of detection of the sensor:

- A FOV value $\Theta$ corresponded to half of the detection field formed by half straight line [Ox) and [OM). Thus a FOV of $20^{\circ}$ corresponded to a total detection field of $40^{\circ}$. If the center of gravity of the cyclist was inside the 
detection field without consideration of the distance (infinite detection range inside the cone), then the cyclist was considered as detected.

- The range detection was defined as a circle with a radius of $\rho$ around the geometric center of the vehicle. It can almost be assimilated to a sensor located in front of the windscreen as a camera. Similarly, if the center of gravity of the cyclist was inside the range detection circle (i.e. $360^{\circ} \mathrm{FOV}$ ), then the cyclist was considered as detected.

Detection rates for values of FOVs between $10^{\circ}$ to $70^{\circ}$ and ranges from $5 \mathrm{~m}$ to $45 \mathrm{~m}$ are computed in this study. Those values include some values that can be found in Hamdane et al (2015) and the FOV is extended to higher value due to a possible effect of cyclist position due to speed. In the current paper, occlusion was considered only for the duration calculation before reaching the LTTB position.

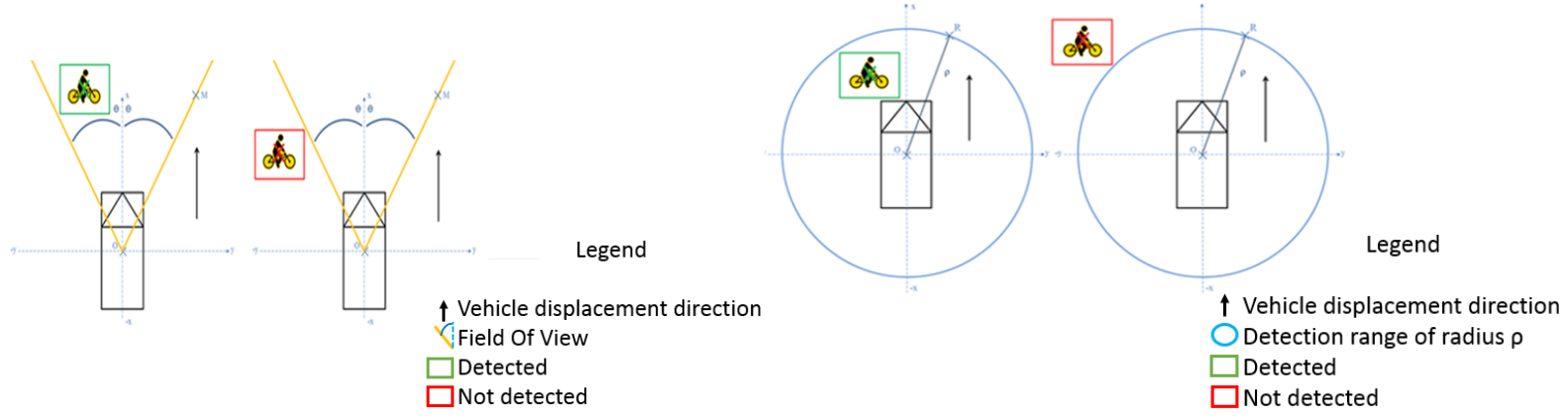

Figure 1: FOV and range sensors modeling

\section{Results}

\subsection{Accident modeling results}

After clustering, the proportion of accidents by scenario is given in Figure 2. The Turning scenario accounted for $34 \%$ of the cases, followed closely by the $\mathrm{CN}$ scenario (33\%), the CF scenario (22\%) and the L scenario which only represented $5 \%$ of the cases. The Turning scenarios consisted of about $12 \%$ of turning left cases and about $22 \%$ of turning right cases. The remaining scenarios classified as "Others" as they do not enter into one of the previous scenarios account for $6 \%$.

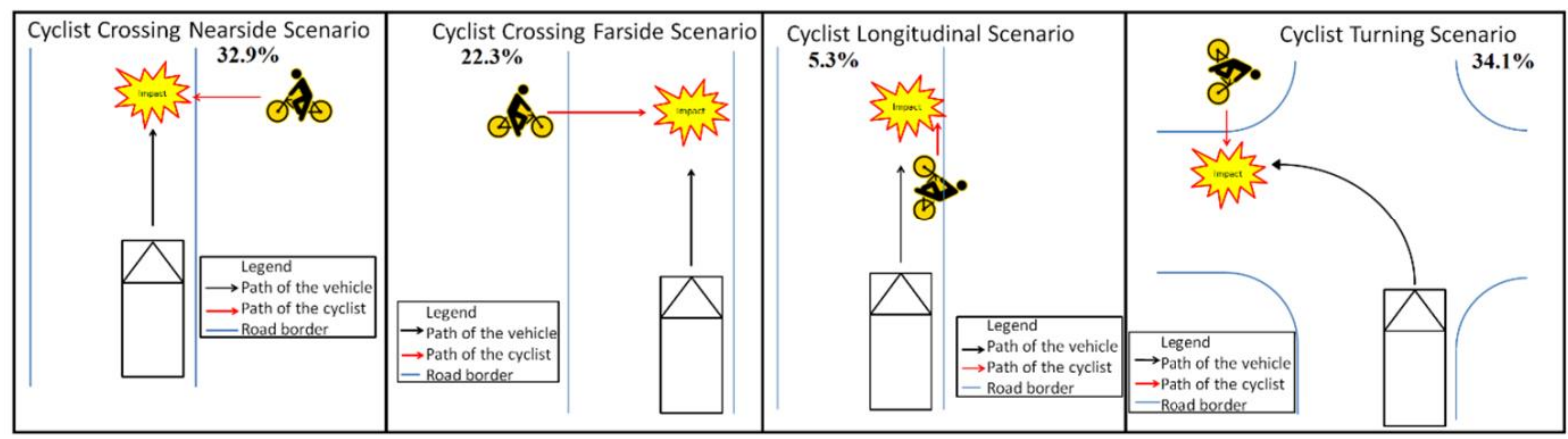

Figure 2: Description and proportion of the 4 main crash scenarios

In order to better visualize the positions of the cyclists relative to the vehicles, Figure 3 shows cyclists' positions relative to the center of the vehicle for TTC $2 \mathrm{~s}, 1.5 \mathrm{~s}, 1 \mathrm{~s}$ and $0.5 \mathrm{~s}$ for all 2261 accidents considered in this study. Figure 3 shows that cyclists were scattered $2 \mathrm{~s}$ before the impact but are within $40 \mathrm{~m}$ ahead from the vehicle front and $-/+20 \mathrm{~m}$ laterally to the car center line.

At TTC 1 second, most of cyclists were at a lateral distance to the car center line smaller than $5 \mathrm{~m}$ and less than $20 \mathrm{~m}$ ahead of car front. At TTC $0.5 \mathrm{~s}$, cyclists are mostly located in front of the vehicle and within $-/+5 \mathrm{~m}$ laterally to the car center. Appendix A shows more details of cyclists' relative positions to the car per scenario. 

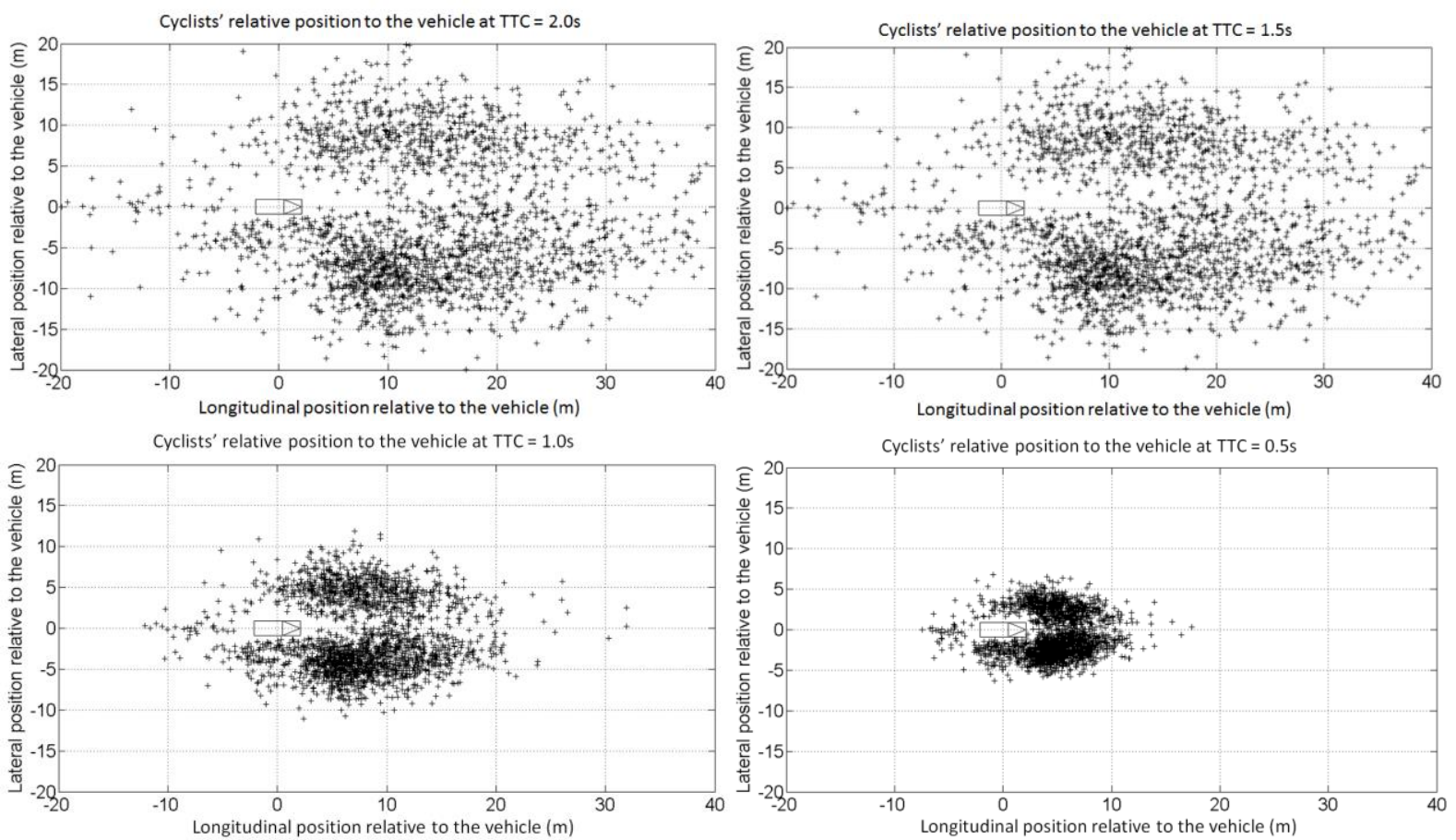

Figure 3: Cyclists' positions relative to the vehicle $2 \mathrm{~s}, 1.5 \mathrm{~s}$, $1 \mathrm{~s}$ and $0.5 \mathrm{~s}$ before the impact.

Additionally, the brake trigger by the driver was also extracted from the accident databases. Among all cases $(\mathrm{CN}$, CF, L, TL, TR and Others), only 33\% of drivers braked before colliding with the cyclist. The brake trigger took place less than $1 \mathrm{~s}$ before the impact for $80 \%$ of the drivers who had activated the brakes (see Figure 4). This proportion was slightly above $50 \%$ of the drivers for brake activation at TTC $0.5 \mathrm{~s}$. Table 1 indicates the percentage of brake activation per scenario. The rate reached a minimum of $28.9 \%$ for $\mathrm{CN}$ up to $37.7 \%$ for $\mathrm{CF}$.

\begin{tabular}{llllll}
\hline Scenario & CN & CF & L & TL & TR \\
\hline Brake activation percentage (\%) & 28.9 & 37.7 & 33.3 & 34.6 & 31.9 \\
Total cases in the scenario & 744 & 504 & 120 & 280 & 492 \\
\hline
\end{tabular}

Table 1: Brake activation percentage per scenario.

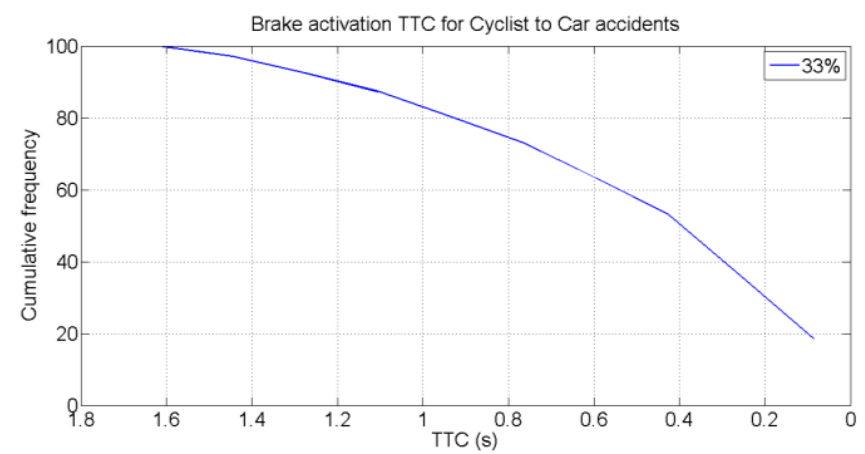

Figure 4 : Cumulative frequency of brake activation timing (all car-to-cyclist accidents, $\mathrm{N}=2261,33 \%$ of all cases).

The cyclists' speed was estimated in $80 \%$ of all cases close to or below $20 \mathrm{~km} / \mathrm{h}$ (sees Appendix B). There was only some slight difference for the $\mathrm{CN}$ where $90 \%$ of the cyclists were estimated as having a speed near or below $20 \mathrm{~km} / \mathrm{h}$. Cyclists speed was higher compared to the $5 \mathrm{~km} / \mathrm{h}$ for a walking pedestrian (Huang et al. 2008).

\subsection{Relevant parameters for ADAS}

This part presents different results that can be relevant for the design of ADAS and is independent from results extracted in part 3.1. The range and FOV rate detection rates during accident progresses are computed to indicate sensor detection requirements. The detection rates per FOV are also computed at the last time to brake in second 
to indicate when to activate brake with the help of which FOV. Finally, the proportion of detected cyclist per FOV in function of the visibility duration before the last time to brake is given in order to indicate the available time for an ADAS to collect and process data and trigger before that critical instant.

Figure 5 shows the detection rate by FOV at different TTCs. It corresponds to the detection rate that can be reached for a given FOV during the progress of an accident. Occlusion of the cyclist by potential obstacles was not considered in figure 5.

For values of FOVs lower than $40^{\circ}$, detection rates increased as the kinematic of the accident progresses. Indeed, the closer to the impact, the more cyclists enter the FOV as initially they were not detected. This trend concerns $40^{\circ} \mathrm{FOV}$ or lower. For value of FOVs higher than $40^{\circ}$, the detection rate increased and then decreased at a TTC of about $0.4 \mathrm{~s}$ before the collision. The evolution of those curves could be explained by the kinematic progress of the accident with alternation between detected (in the FOV) and not detected phase (out of the FOV). Thus in some situations, where initially the cyclist was in the FOV, this may not be the case anymore when moving closer to the collision time (impact) as the cyclist may be at the vehicle side (outside the detection cone). This last trend concerns FOV values higher than $50^{\circ}$. Additionally, starting from FOV values of $50^{\circ}$, the gain became smaller and smaller when FOV increased.

Detection rates went from about $15 \%$ for FOV $10^{\circ}$ to approximately $90 \%$ for FOV of $70^{\circ} 2 \mathrm{~s}$ before the impact. Except for curves that kept increasing, the maximal detection rate lay around a TTC of $0.4 \mathrm{~s}$ with a little more than $90 \%$ of cyclists detected for FOV $70^{\circ}$.

Whatever the scenarios considered, some cyclists remained outside the detection field of view for the highest FOV value of $70^{\circ}$. It could correspond for example to situation where the cyclist collided the car on the side. Results evolved in a similar way for $\mathrm{CN}$ and $\mathrm{CF}$, and for TL and TR scenarios. For $\mathrm{CN}$ and $\mathrm{CF}$ configurations, detection rates for FOV between $10^{\circ}$ to $40^{\circ}$ seem to be stable and increased from a TTC of $1 \mathrm{~s}$. For FOVs from $50^{\circ}$ to $70^{\circ}$, the detection rate reached a maximum value of about $90 \%$ at a TTC of about $0.5 \mathrm{~s}$ and decreased to the impact. At TTC 2s, an important gain could be noticed between each FOV with a gain reduction between FOV $60^{\circ}$ and $70^{\circ}$. From a general point of view, the additional gain was small from a FOV above $60^{\circ}$.

For L scenario, the detection curves all decreased as the vehicle got closer to the cyclist. This evolution could be easily understood because of cyclist relative position to the car during the accident. If the cyclist was not in front of the car but on the side, the closer the cyclist was to the vehicle's sensor, the higher FOV was needed to detect the cyclist. This phenomenon is particularly visible for L scenario as initially cyclists were already detected. The decrease detection rate was more visible for smaller FOVs than for higher one. Different detection cones in each sub-figure of Annex A have been drawn to help visualizing the decreasing detection rates particularly visible for L scenario. Annex A sub-figures illustrate the results visible in Annex C sub-graphs. TL scenario reached the highest detection rate at $1 \mathrm{~s}$ TTC while in TR, CN and CF scenarios the highest detection rate was observed at 0.2 TTC. Appendix C shows FOVs detection rates for each scenario.

For L scenario, the highest detection rate was about $80 \%$ and was reached between 2 and 1s TTC for FOVs higher than $40^{\circ}$. A decreased was observed from $0.4 \mathrm{~s}$ TTC. This evolution was due to the scenario configuration as the kinematic progresses. When the cyclist was far away from the car, the cyclist was inside the detection cone in front of the car. When the distance between the car and the cyclist was reduced to a certain point, the cyclist left the field of detection. This was explained by the cyclist position when riding on the road. Indeed, cyclists rarely stayed in the middle of the road and mostly rode on the right side of the road. Thus, when getting closer to the car, cyclists "left" the detection field due to their position on the right side of the road.

Figure 5 shows also the detection rate according to the range (distance between car center and cyclist center). As expected, the higher the range was, the more cyclists could be detected earlier during the kinematic sequence. For detection range above $30 \mathrm{~m}$, more than $90 \%$ of cyclists could be detected $2 \mathrm{~s}$ before the impact. This rate nearly reaches $100 \%$ if the range is $45 \mathrm{~m}$ at TTC $2 \mathrm{~s}$. Thus $35 \mathrm{~m}$ appears to be the appropriate detection range as the gain is small between 35 and $45 \mathrm{~m}$ at TTC $2 \mathrm{~s}$ and close to $100 \%$. Table 2 shows the detection variation for some ranges at TTC 2 s for the different scenarios. 

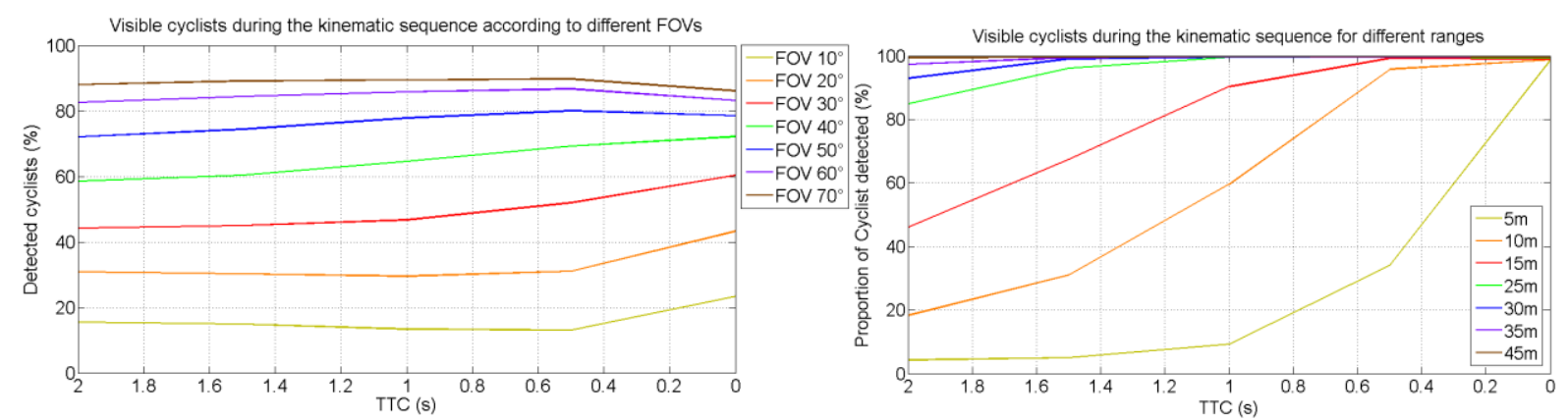

Figure 5: Rate of visible cyclists at different TTC for different FOVs (Left) and ranges (Right)

\begin{tabular}{llllll}
\hline TTC 2s & CN & CF & L & TR & TL \\
\hline $15 \mathrm{~m}$ & $47 \%$ & $37 \%$ & $55 \%$ & $60 \%$ & $22 \%$ \\
$35 \mathrm{~m}$ & $98 \%$ & $99 \%$ & $95 \%$ & $100 \%$ & $92 \%$ \\
\hline
\end{tabular}

Table 2: Detection rates per ranges for each scenario.

Cyclist detection rates are given according to the last time to brake criterion ( $\mathrm{t}_{\mathrm{LTTB}}$ ) in second for different FOVs. Each accident where the kinematic is known has a LTTB in meter. $\mathrm{t}_{\mathrm{LTTB}}$ is the time to travel from the LTTB position (computed using equation 1) to the impact location and corresponds to a duration. Thus, $\mathrm{t}_{\mathrm{LTTB}}$ gives the same information as the LTTB but instead of a distance in meters the information given is a time in seconds. From there, figure 6 left part shows the cumulative frequency of detected cyclists per FOV in function of the $t_{\text {LTTB. }}$. Little gain can be observed with $t_{\text {LTTB }}$ higher than 1 s, i.e. more than 1 second before the collision. To be able to detect $50 \%$ of the cyclists at a $t_{\text {LTTB }}$ of $1 \mathrm{~s}$, a FOV of $30^{\circ}$ would be needed. With a FOV of $60^{\circ}$ at the same $t_{\text {LTTB }}$ of $1 \mathrm{~s}$, the detection rate is increased up to more than $80 \%$. The higher slope for large value of FOVs shows that this parameter has an essential role when the last time to trigger brake is less than $1 \mathrm{~s}$ before the collision (i.e. $\mathrm{t}_{\mathrm{LTTB}}<1 \mathrm{~s}$ ). Additionally, the detection rates reach a maximum value of about $85 \%$. It means that in about $15 \%$ cases, the cyclist is not detected when the vehicle is supposed to initiate a braking manoeuver.

Figure 6 right part shows the results for the realistic braking model. It can be remark that, no $t_{\text {LTTB }}$ value can be found $0.1 \mathrm{~s}$ before the impact due to the progressive rise of the deceleration value. The maximum detection rate per $t_{\text {LтTB }}$ is also affected and is a little lower compared to the ideal model. It is more visible for low FOV values and can be neglected for higher values. An ANOVA test with a $0.05 \mathrm{p}$-value has been performed in order to determine if a statistical difference appears compared to the ideal braking model. The results of the test can be summarized in table 3. No statistical difference is observed for FOV values $50^{\circ}$ and higher per scenario and for all accidents. Also no difference can be observed for the L scenario whatever the FOV due to the trajectories of both car and cyclist. This way, the FOV is not affected even if $\mathrm{t}_{\mathrm{LTTB}}$ are shifted a little later compared to the ideal braking model. It can be highlight that for FOV values $40^{\circ}$ and lower, some statistical difference can be observed. This phenomenon is due to the shift in the $t_{\text {LTTB }}$ value. The faraway the car is, the higher detection angle is required. This way, lower values of FOV are affected. Another remark that can be highlight is that even if "small" statistical difference is observed per scenario, these differences are cancelled for FOV higher than $40^{\circ}$ when all scenarios are considered. As there is no statistical difference for FOV values higher than $40^{\circ}$ for all accidents cases, the ideal braking model has been kept for the analysis in the next part.
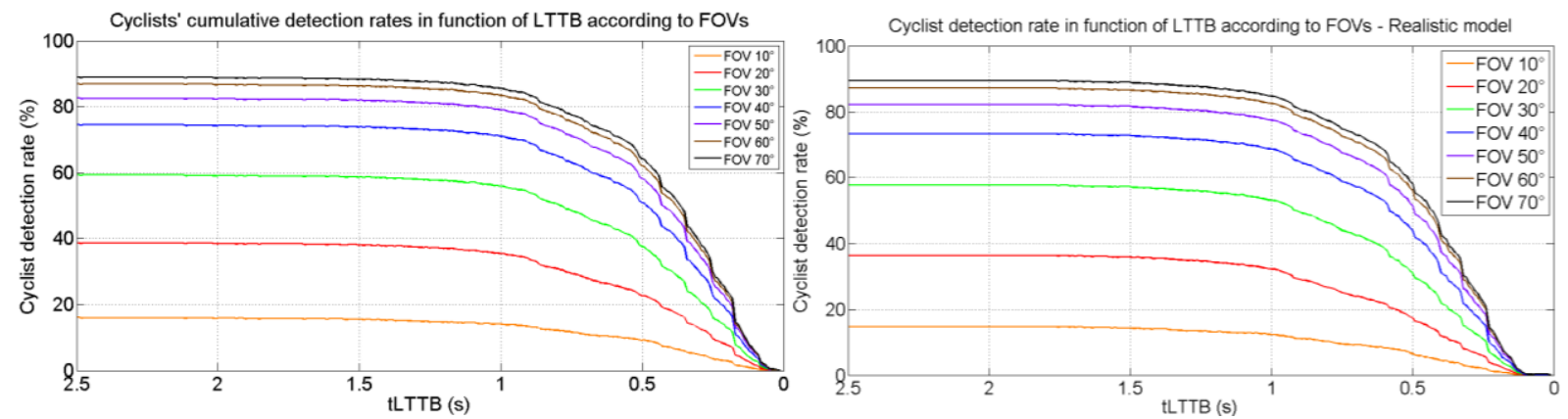

Figure 6: Cyclist cumulative detection rates in function of $\mathrm{t}_{\mathrm{LTTB}}$ for different FOVs with ideal braking model (left) and realistic braking model (right) 


\begin{tabular}{lllllllll}
\hline $\begin{array}{l}\text { Scenario } \\
\text { / FOV }\end{array}$ & 10 & 20 & 30 & 40 & 50 & 60 & 70 & \\
\hline & F & F & F & F & F & F & F & $\begin{array}{l}p \\
\text { value }\end{array}$ \\
& & & & & & & & \\
CN & 33,556 & 29,249 & 9,715 & 3,994 & 1,950 & 1,751 & 1,112 & 3.859 \\
CF & 92.585 & 7.504 & 2.912 & 4.067 & 2.648 & 1.143 & 0.776 & 3,859 \\
L & 0,180 & 0,012 & 0,227 & 0,251 & 0,273 & 0,717 & 0,719 & 3.859 \\
TR & 9,396 & 39,285 & 5,323 & 4,250 & 2,389 & 0,978 & 1,225 & 3.859 \\
TL & 3,917 & 0,164 & 1,617 & 1,269 & 0,991 & 0,482 & 0,705 & 3.859 \\
All & 11.965 & 10.700 & 4.277 & 3.069 & 1.794 & 1.097 & 0.907 & 3.859 \\
\hline
\end{tabular}

Table 3: results of the ANOVA test between the ideal and the realistic braking model

Appendix D shows the detection rates at $\mathrm{t}_{\text {LTTB }}$ for each scenario. Some cyclists are not detected at that critical moment which is the last time to react in order to avoid the accident. Similarities can be observed for $\mathrm{CN}$ and $\mathrm{CF}$

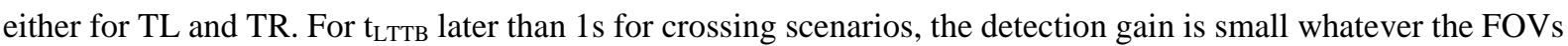
whereas for turning scenarios, the gain is small for detection at a $t_{\text {LTTB }}$ later than $0.75 \mathrm{~s}$. Contrary to crossing and turning scenarios, detection rates keep increasing in $\mathrm{L}$ scenario which indicates that the $\mathrm{t}_{\mathrm{LTTB}}$ could go up to a value of $2.5 \mathrm{~s}$. An important point which can be noticed is that detection rates gain for value higher than $50^{\circ}$ becomes smaller and smaller.

One important parameter is the available time for the device to detect, analyze and then trigger a FCW or an AEB. The available time for a system to react depends on the visibility of the VRU. Calculus must then take into account occlusion factor in order to assess correctly the available duration for system to collect data, analyze and react in real accident situations. Thus occlusion is taken into account here.

Figure 7 shows the rate of detected cyclists per FOVs in function of a duration tvisible- $t_{\text {LTTB. }}$ tvisible- $t_{\text {LTTB }}$ is the duration from the $1^{\text {st }}$ time the cyclist is not occluded (tvisible) by the surrounding environment to the $t_{\text {LTTB. It can }}$

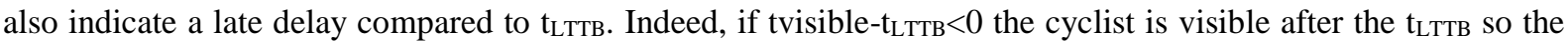
accident could not be avoided by an emergency braking because a safety device (AEB or FCW) would trigger too late but could be perhaps mitigated. When tvisible- $\mathrm{t}_{\text {LTTB }}>0$, it signifies that the duration tvisible- $\mathrm{t}_{\text {LTTB }}$ corresponds to the amount of time available from the first time the cyclist is not occluded to the $t_{\text {LTTB. This means that a safety }}$

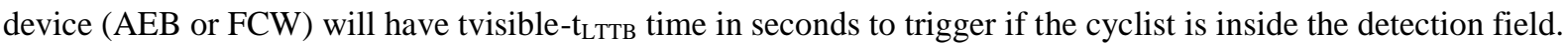
Each detection values in figure 7 thus indicate the cyclist cumulative detection rate for duration value equal to tvisible- $\mathrm{t}_{\text {LTTB }}$ or more. For example, if we consider a detection rate for a value of tvisible- $\mathrm{t}_{\mathrm{LTTB}}$ of $2 \mathrm{~s}$, then the detection value corresponds to all cyclists that can be detected at least $2 \mathrm{~s}$ before the $t_{\mathrm{LTTB}}$.

For duration of tvisible- $\mathrm{t}_{\text {LTTB }}$ of 4 seconds with a FOV $60^{\circ}$, about $51 \%$ of cyclists could be detected whereas only $16 \%$ could be detected for a FOV $10^{\circ}$. The closer tvisible is to $t_{\mathrm{LTTB}}$, the more cyclists could be detected whatever the FOVs. When tvisible is equal to $\mathrm{t}_{\mathrm{LTTB}}$, i.e. for $\mathrm{x}$-axis 0 in figure 7 , detection rates reached nearly the maximum value for each curves with $80 \%$ detected for FOV $60^{\circ}$ and $19 \%$ for FOV $10^{\circ}$. One could notice that the curves still slowly increased for negative duration, i.e. for tvisible $<\mathrm{t}_{\mathrm{LTTB}}$. This means that there were cases where at the moment when the brakes should be triggered to avoid the collision, the cyclists were not inside sensors' detection field. It concerns only a very few percent of cases but it still indicated for those cases that only mitigation could be possible.

Results per scenario had been extracted and had the same evolution as figure 7. Only for L scenarios, FOV variation has no effect on the detection rates due to the scenario configuration as all curves overlap.

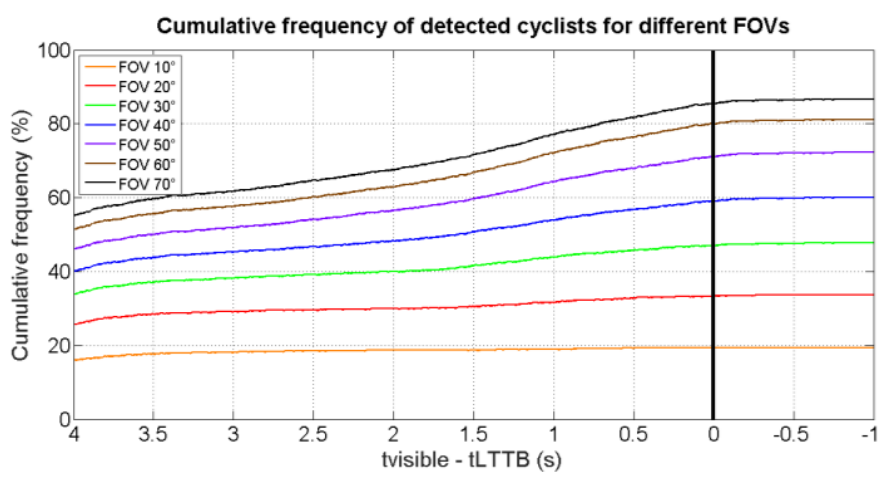


Figure 7: Cumulative frequency of detection rates per FOVs in function of the visibility duration. The cyclist is seen (duration in seconds) before the $\mathrm{t}_{\mathrm{LTTB}}$ when $\mathrm{X}$-axis value is positive whereas when $\mathrm{X}$-axis is negative the

cyclist is seen too late after $\mathrm{t}_{\mathrm{LTTB}}$.

\section{Discussion}

This research aims at understanding and determining the characteristics of accidents prior to collision. To that end, an analysis of 2261 accident cases was performed.

Crash scenario reconstructions greatly rely on available data gathered by in-depth investigation teams and on the accuracy of the reconstructions.

A detection estimation of such device is realized through computational calculation of crash scenarios. During those simulations, there is no consideration of weather or illumination conditions which can affect the detection. The detection rates do not take into account the dynamic surrounding of the accident scene to determine global FOV and range characteristics. The changeover between visible, hidden, visible VRU greatly depends on the traffics environment and is rarely known before or at the time of the collision. Thus, detection rates presented in this study are optimistic results. Additionally, some reasonable assumptions are done, as the value of deceleration coefficient applied to determine the LTTB, sensor's position or the brake trigger during the original accident kinematic reconstructions. From a general point of view, the detection rate never reaches $100 \%$ since some cyclists can never be detected because they remain outside the detection field even at the moment of the accident leading to a lateral collision. In regard to parameters considered for an ADAS device, only braking manoeuvers were considered. Steering manoeuvers are not considered since this manoeuver needs to take into account many others factors such as traffic situation, opportunity to make this evasive manoeuver (Hayashi et al. 2012).

Hamdane et al. (2015) analyzed parameters for an AEB for pedestrian based on real accidents and determined that a FOV of $35^{\circ}$ was optimum for pedestrians' detection. Additionally, he shows that the needed AEB trigger time has a great influence on the avoidance rate. Indeed, this rate decreased from more than $80 \%$ if the AEB trigger is immediate ( $0 \mathrm{~s}$ is needed to trigger the AEB) to $75 \%$ (respectively 64\%) if the AEB needs 0.5 s trigger time (resp. 1s). Lenard et al. (2018) also analyzed parameters for an AEB applied to a British sample of 175 pedestrians and 127 cyclists' cases. Their study showed that with the same FOV definition as the one in this study, an AEB system with a FOV of $80^{\circ}$ is enough to detect $90 \%$ of cyclists and $20^{\circ}$ for pedestrians. Similarly to Lenard et al. study, this research also shows that higher FOVs allow detecting more cyclists. Detection rate values may be of interest for car manufacturers for FOV values higher than $50^{\circ}$ for cyclist safety as there is still a detection gain even if it is smaller and smaller. As an AEB should trigger at TTC $1 \mathrm{~s}$, a $20 \mathrm{~m}$ range is sufficient whereas $35 \mathrm{~m}$ is needed for a FCW trigger at TTC $2 \mathrm{~s}$. Thus it appears that a range of $35 \mathrm{~m}$ appears to be sufficient to nearly detect all cyclists about 2 seconds before the collision. Independent analysis can be performed on range and FOV as during the kinematic, the closer to the collision time, the closer the cyclist are. The range parameter does not influence the detection rates which mostly rely on the FOV. Last but not least, this study gives a first insight of the optimist detection rate a device could achieve before the last moment to trigger brakes. The sample used in this paper is not representative of national accident proportion and is a limitation of this work. Application of weighting factors could allow being representative. Values given are thus indicative of potential detection rates. For a FOV of $60^{\circ}$, about $51 \%$ of cyclists can already been detected at least $4 \mathrm{~s}$ before the $t_{\text {LTTB }}$ whereas this rate reaches $72 \%$ if the cyclist is detected at least $1 \mathrm{~s}$ before $t_{\text {LTTB }}$. For a FOV of $40^{\circ}$, the rate reaches $40 \%$ and $54 \%$ if the cyclist is detected

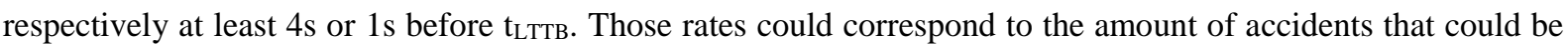
potentially avoided. Similar effectiveness value can be found in Ohlin et al. (2017). They estimated on Swedish data that $70 \%$ effectiveness can be obtained for pedestrians and cyclists through the combination of different measures and AEB technology. Rosén (2013) worked on AEB effectiveness on GIDAS PCM data. His analysis on 607 accidents revealed that depending on the AEB systems parameters, AEB could be effective on 55\% fatal cases and 33\% severe injured cases. To be comparable to Rosén work, results in this study have to be adapted to the injury criteria but it shows the potential of such ADAS for cyclist safety. Compared to an AEB, the FCW design has to be taken into account more carefully as another component has to be included: driver's reaction.

In the case of a FCW, results found in this paper can give an indication of the time where the warning can be delivered to driver with consideration of his time reaction. It can also give an indication of the time available for an AEB system to reach full efficiency with consideration of the transient state. The choice of the ADAS trigger timing becomes a crucial parameter due to driver reaction time for the case of a warning device like a Forward Collision Warning. Depending on many criteria like the driving environment and the state of mind of the driver, the driver reaction to a signal can therefore vary as shown in the review of Young and Staton (2007). WarshawskyLivne and Shinar (2002) showed that the brake reaction time of a driver is increased by uncertainty and age. Thus, the perception-reaction time which is the time from the perception of a signal to the first movement of foot on the 
accelerator is increased from 0.35 to $0.43 \mathrm{~s}$ with age. Also depending on the driving environment situation, Abe and Richardson (2005) showed that the braking reaction time can be affected with consideration to an alarm warning timing for a relatively low driving speed. In a situation where a leading vehicle decelerates rapidly, brake response time can be reduced compared to the situations where no alarms are given. Indeed, the mean duration from a leading vehicle braking event to the application of the brake of the participants' vehicle goes from 0.88 to $1.11 \mathrm{~s}$ depending on the trigger of the alarm and the leading vehicle deceleration. Thus, in this paper, if drivers react in a similar way as those in Abe and Richardson, a FCW should trigger at about a tvisible- $\mathrm{t}_{\text {LTTB }}$ of about $1 \mathrm{~s}$ in order for drivers to be able to avoid the accident. Under the condition of Abe and Richardson for example, with a FOV of $60^{\circ}, 72 \%$ of the cyclist accidents could be avoided using a FCW.

\section{Conclusion}

Field of detection, range of detection and available time before the $t_{\text {LTTB }}$ are keys parameters for car active safety device to reduce the number of cyclist accidents. Through the analysis of 2261 accidents cases ( 30 from French EDA, 2231 from German GIDAS-PCM) involving one passenger car and one cyclist, reconstructions provide information relative to the accident configurations like trajectories of the vehicle and the cyclist, travelling speed, position in time and space. From this analysis, more than $50 \%$ accident cases concern a crossing situation (nearside and farside combined). The FOV and the available time before the $\mathrm{t}_{\mathrm{LTTB}}$ appear to be the critical parameters to detect the cyclist. Similarly to pedestrian accidentology, the most critical period remains between 0 to 1 s before the collision as the cyclist is close or in car's path.

Some critical parameters for ADAS were analyzed: the FOV, the range and the $\mathrm{t}_{\mathrm{LTTB}}$. A FOV of $60^{\circ}$ allows detecting about $80 \%$ of cyclists at a $\mathrm{t}_{\mathrm{LTTB}}$ of $1 \mathrm{~s}$. If driver reaction time is considered to be equal to $1 \mathrm{~s}$ and if a FCW can be triggered $1 \mathrm{~s}$ before the $t_{\text {LTTB }}$ with a FOV $60^{\circ}$, about $72 \%$ accident cases could potentially be avoided. A range of $35 \mathrm{~m}$ appears to be sufficient to nearly detect all cyclists $2 \mathrm{~s}$ before the collision.

Even if results are optimistic, this study gives indications about the characteristics that active safety device for cyclist ADAS should have. It also gives information of the characteristic ADAS should have if equipped with adaptive sensors. Further work will focus on the FCW effect estimation on cyclist accident.

\section{Acknowledgement}

The authors thank Toyota Motor Europe for accessing GIDAS-PCM database and their collaboration to this research.

Funding: This work was supported by Toyota Motor Europe.

\section{References}

Abe G., Richardson J., 2005, The influence of alarm timing on braking response and driver trust in low speed driving, Safety Science, vol. 43, pp. 639-654, DOI: 10.1016/j.ssci.2005.04.006.

Brach R.M. and Brach R.M., 2005, Vehicle Accident Analysis and Reconstruction Methods, SAE International.

Byatt R. and Watts R., 1981, Manual of Road Accident Investigation, Pitman.

Coelingh E., Eidehall A., Bengtsson M., 2010, Collision Warning with Full Auto Brake and Pedestrian Detection - a practical example of Automatic Emergency Braking, $13^{\text {th }}$ International IEEE Annual Conference on Intelligent Transportation Systems, Madeira Island, Portugal, pp. 155-160.

Euro NCAP, 2017, Test protocol - AEB VRU systems Version 2.0.2, EUROpean New Car Assessement Program.

Euro NCAP, 2018, URL https://www.euroncap.com/fr/s\%C3\%A9curit\%C3\%A9-des-v\%C3\%A9hicules/lanotation-en-d\%C3\%A9tail/protection-des-usagers-vuln\%C3\%A9rables-de-la-route-vru/aeb-cycliste/, (accessed September 2018).

Ferrandez F., Brenac T., Girard Y., Lechner D., Jourdan J.-L., Nachtergaele C., Michel J.-E., 1995, L’étude détaillée d'accidents orientée vers la sécurité primaire. Méthodologie de recueil et de pré-analyse. Convention INRETS/DSCR, Presses de l'Ecole nationale des ponts et chaussées. 
Forkenbrock G., O’Harra B., 2009, A Forward Collision Warning (FCW) Performance Evaluation, Proceedings of the $21^{\text {st }}$ (ESV) International Technical Conference on the Enhanced Safety of Vehicles, Stuttgart, Germany.

GIDAS, 2016, URL https://www.gidas.org/en/about-gidas/gidas-methodik/ (accessed August 2018)

Hamdane H., Serre T., Masson C., Anderson R., 2015, Issues and challenges for pedestrian active safety systems based on real world accidents, Accident Analysis and Prevention, vol. 82, pp. 53-60, DOI: 10.1016/j.aap.2015.05.014.

Hayashi R., Isogai J., Raksincharoensak P., Nagai M., 2012, Autonomous collision avoidance system by combined control of steering and braking using geometrically optimized vehicular trajectory, Vehicle System Dynamics, 50:sup1, 151-168, DOI: 10.1080/00423114.2012.672748.

Høye A., Hesjevoll I. S., Vaa T., 2015, Advanced driver assistance systems - status and future potential, TØI Report 1450/2015, Oslo, 162 pages.

Huang S., Yang J., Eklund F., 2008, Evaluation of remote pedestrian sensor system based on the analysis of carpedestrian accident scenarios, Safety Science, vol. 46, pp.1345-1355, DOI: 10.1016/j.ssci.2007.08.004.

Kuehn, M., Hummel T., Lang A., 2015, Cyclist-car accidents - Their consequences for cyclists and typical accidents scenarios, Proceedings of the 24th International Conference on the Enhanced Safety of Vehicles, Gothenburg, Sweden, paper number 15-0243.

Lechner D. and Ferrandez F., 1990, Analysis and reconstruction of accident sequences, XXIII FISITA Congress, ATA, Torino, Italy, pp. 931-939.

Lenard J., Welsh R., Danton R., 2018, Time-to-collision analysis of pedestrian and pedal-cycle accidents for the development of autonomous emergency braking systems, Accident Analysis and Prevention, vol. 115, pp. 128136, DOI: 10.1016/j.aap.2018.02.028.

Ohlin M., Strandroth J., Tingvall C., 2017, The combined effect of vehicle frontal design, speed reduction, autonomous emergency braking and helmet use in reducing real life bicycle injuries, Safety Science, vol. 92, pp. 338-344, DOI: 10.1016/j.ssci.2016.05.007.

Rodarius C., Kwakkernaat M., Edwards M., de Hair S., Pla M., 2014, Benefit estimate based on previous studies for pre-crash bicyclist systems and recommendations for necessary changes to pedestrian test and assessment protocol (No AsPeCSS D1.5).

Rosén E., 2013, Autonomous Emergency Braking for Vulnerable Road Users, Proceedings of International Research Council on the Biomechanics of Injury, Gothenburg, Sweden, pp. 618-627.

Saadé J., Chajmowicz H., Cuny S., 2019, Prospective Evaluation of the Effectiveness of Autonomous Emergency Braking Systems in Increasing Pedestrian Road Safety in France, Proceedings of International research Council on the Biomechanics of Injury, Florence, Italy.

Schaller T., Aparicio A., Gruber C, Pla M., 2012 Report describing the comparative survey of existing test protocols and test facilities (No AsPeCSS D2.2).

Schubert A., Erbsmehl C., Hannawald L., 2012, Standardized Pre-Crash-Scenarios in digital format on the basis of the VUFO simulation, Proceedings of ESAR Conference, Stuttgart, Germany.

Stoll J., Schneider A., Wisch M., Seiniger P., Schaller T., 2016, The addressed VRU scenarios within PROSPECT and associated test catalogue, PROSPECT Deliverable D3.1.

Uittenbogaard J., Rodarius C., Op den Camp O., 2016a, CATS car-to-cyclist accident scenarios, TNO 2014 R11594 (CATS Deliverable 1.2). 
Uittenbogaard J., Op den Camp O., van Montfort S., 2016b, CATS car-to-cyclist accident parameters and test scenarios, TNO 2014 R11705 (CATS Deliverable 2.2).

Violette E. and Le Bec P.J., 2016, Freinage d'urgence motos vs voitures particulières, Essais sur piste, CEREMA, Rapport.

Warshawsky-Livne L., Shinar D., 2002, Effects of uncertainty, transmission type, driver age and gender on brake reaction and movement time, Journal of Safety Research, vol. 33, pp. 117-128.

WHO, 2015, Global status report on road safety, on-line. World Health Organization (accessed July 2018). http://www.who.int/violence_injury_prevention/road_safety_status/2015/en/

Young M. S., Stanton N. A., 2007, Back to the future: Brake reaction times for manual and automated vehicles, Ergonomics, vol. 50, no. 1, pp. 46-58, DOI: 10.1080/00140130600980789.

Zhao Y., Ito D., Mizuno K., Kong C., 2019, AEB effective evaluations by accident reconstructions using videos of drive recorders in perpendicular and turning car-to-cyclist collisions, Proceedings of International research Council on the Biomechanics of Injury, Florence, Italy.

Appendix A: Cyclists' positions relative to the vehicle $2 \mathrm{~s}, 1.5 \mathrm{~s}, 1 \mathrm{~s}$ and $0.5 \mathrm{~s}$ before the impact for CN, CF, TR, $\mathrm{TL}$ and $\mathrm{L}$ accidents
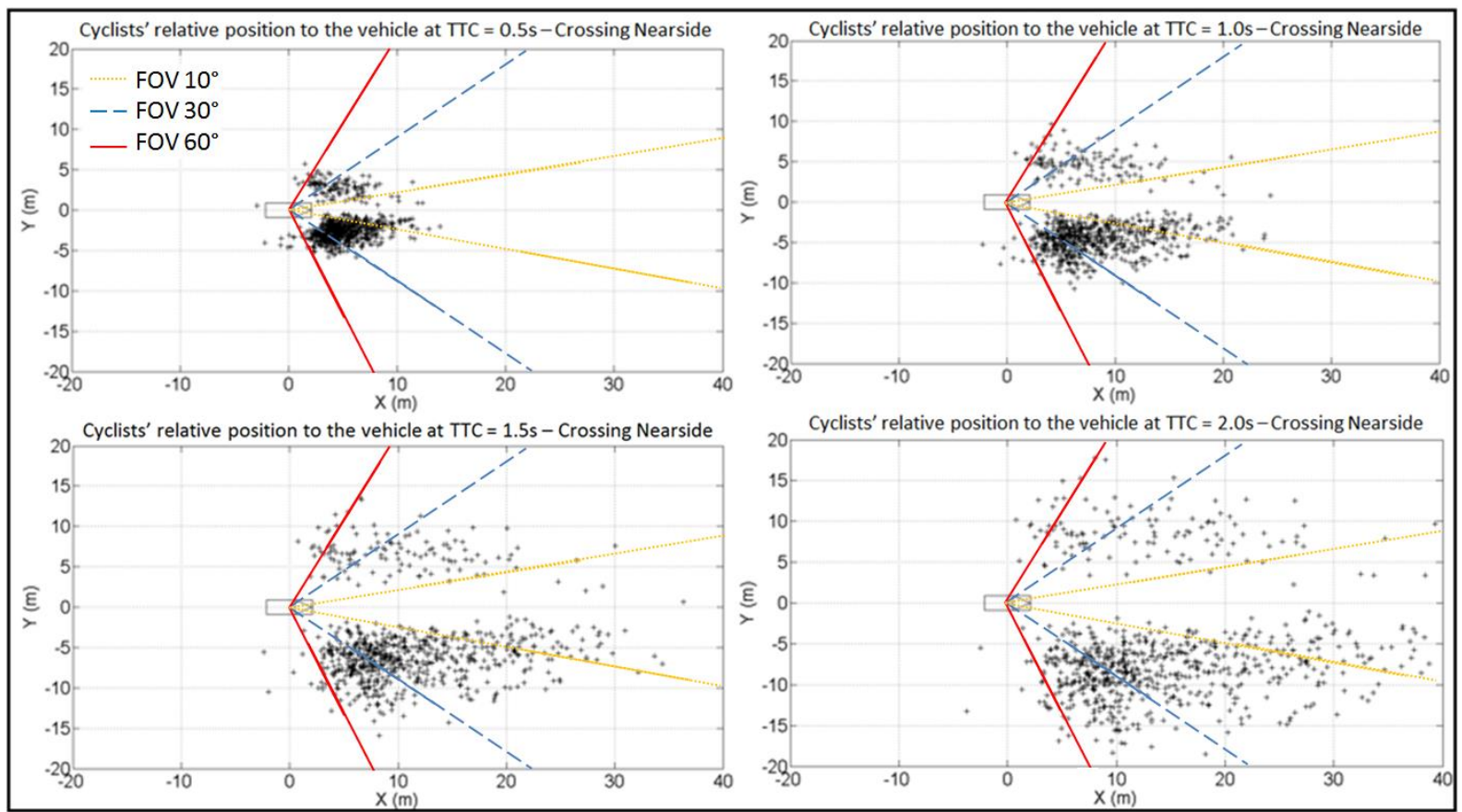


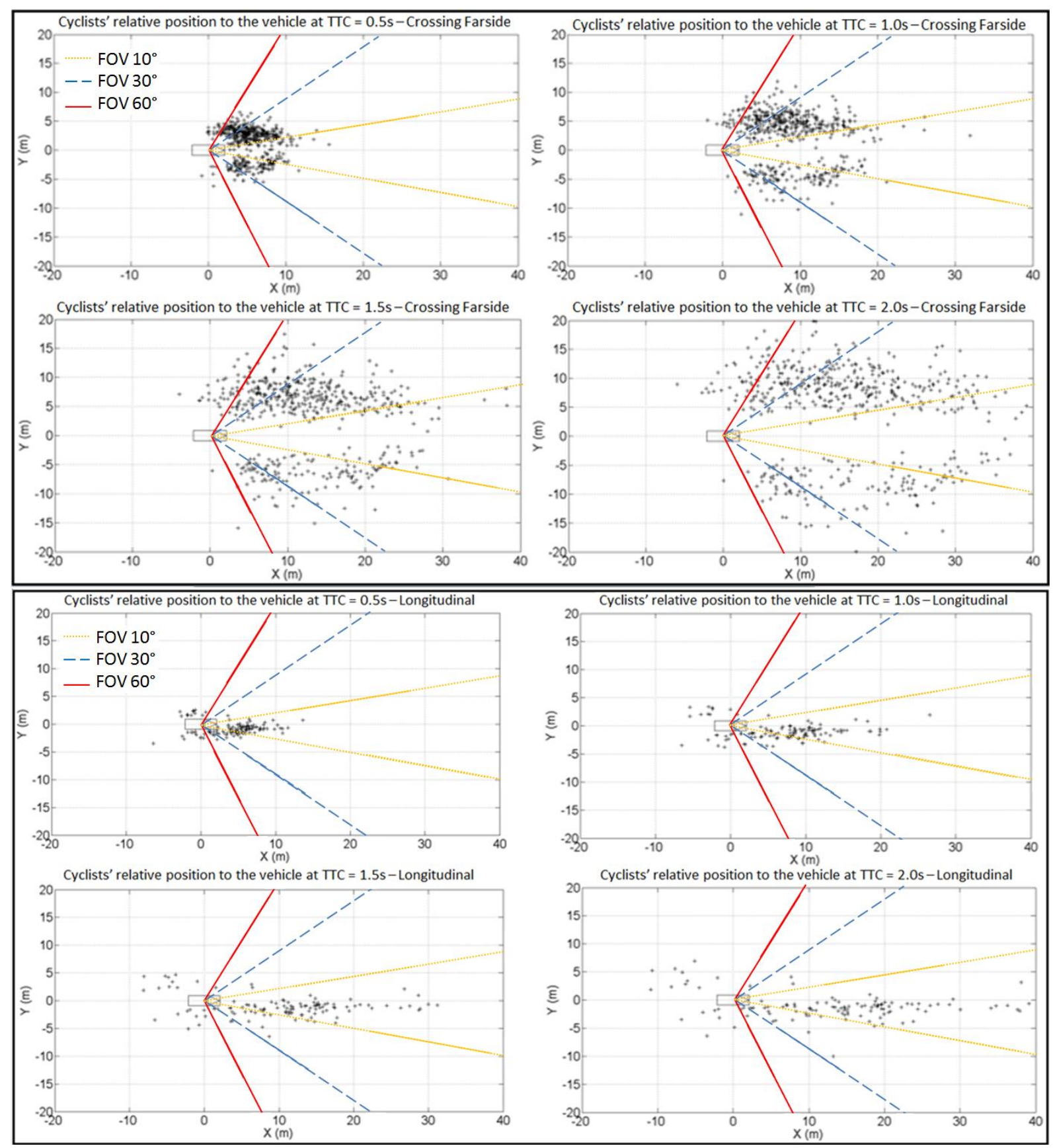



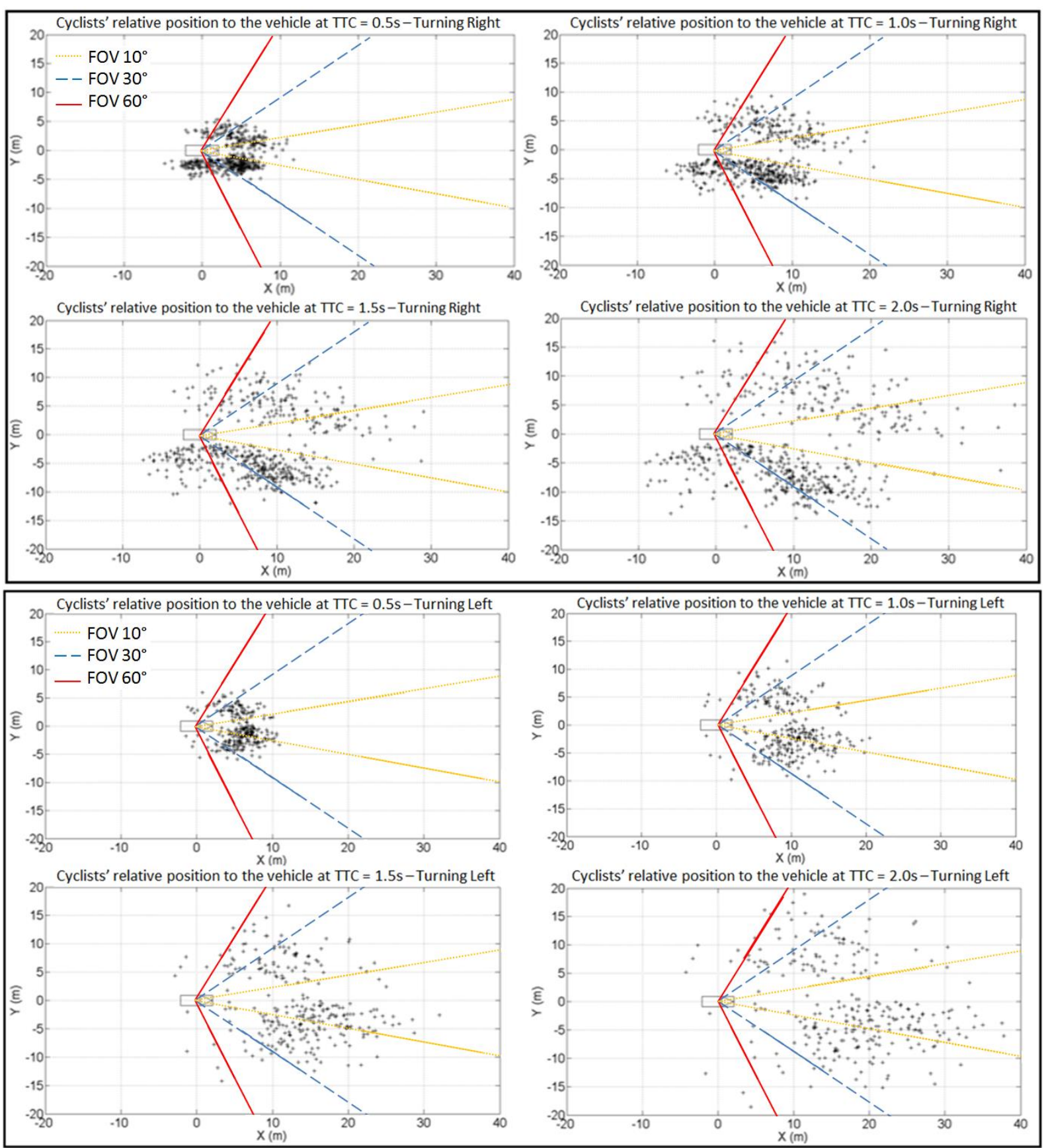

Appendix B: Cyclist speed

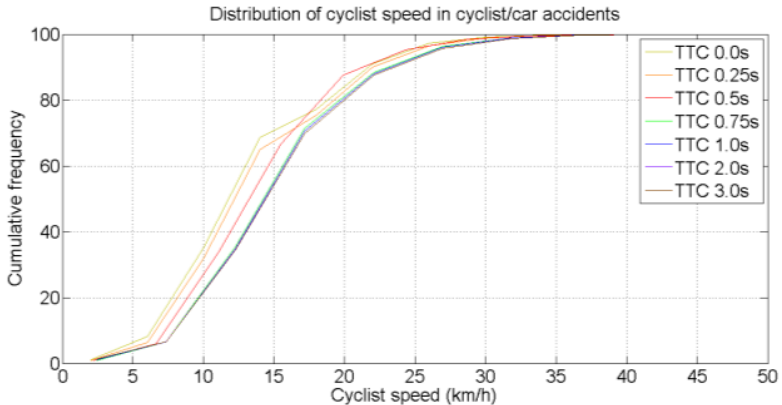

Appendix C: Rates of visible cyclist for different FOVs 

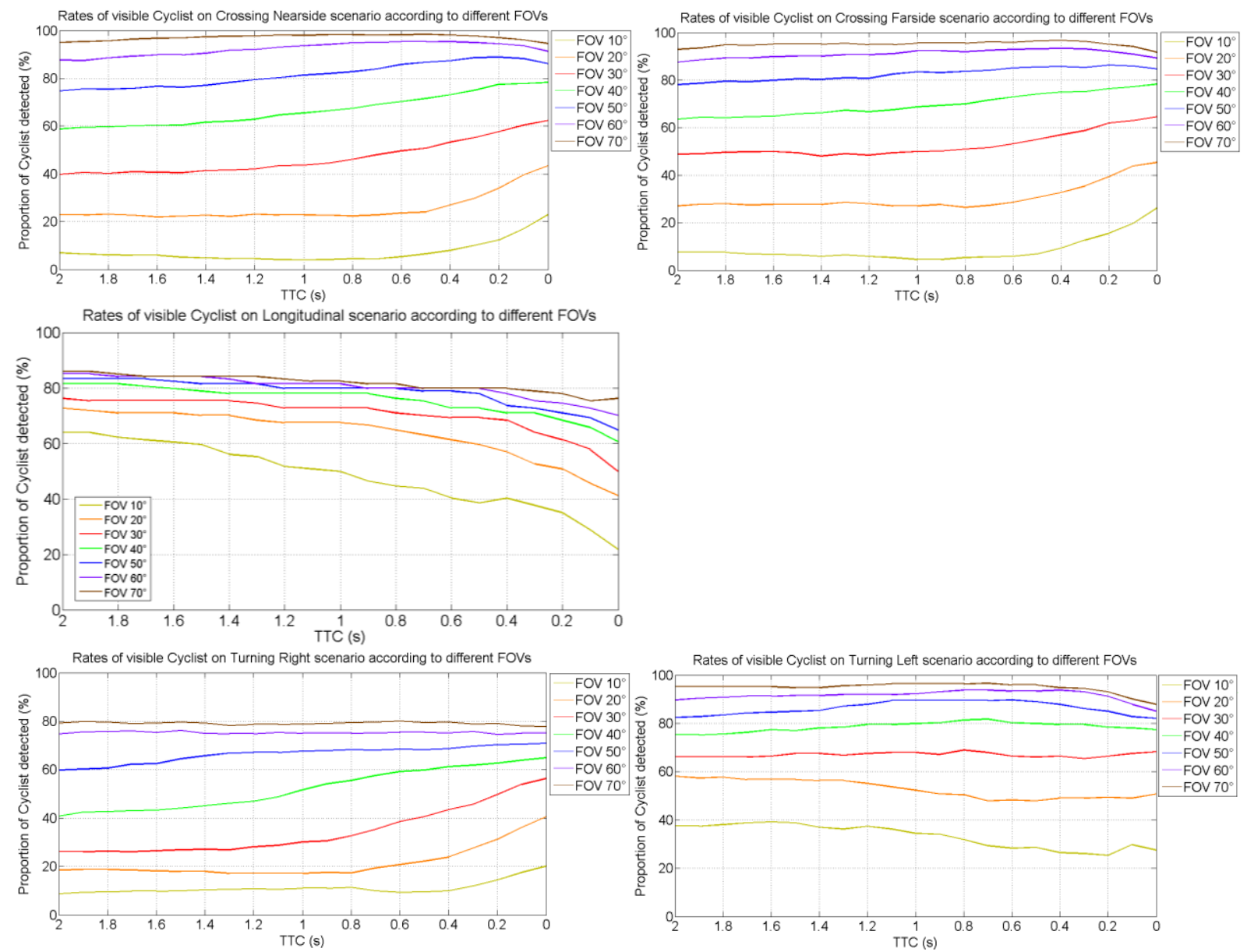

Appendix D: Detection rates at $t_{\mathrm{LTTB}}$ for different FOVs
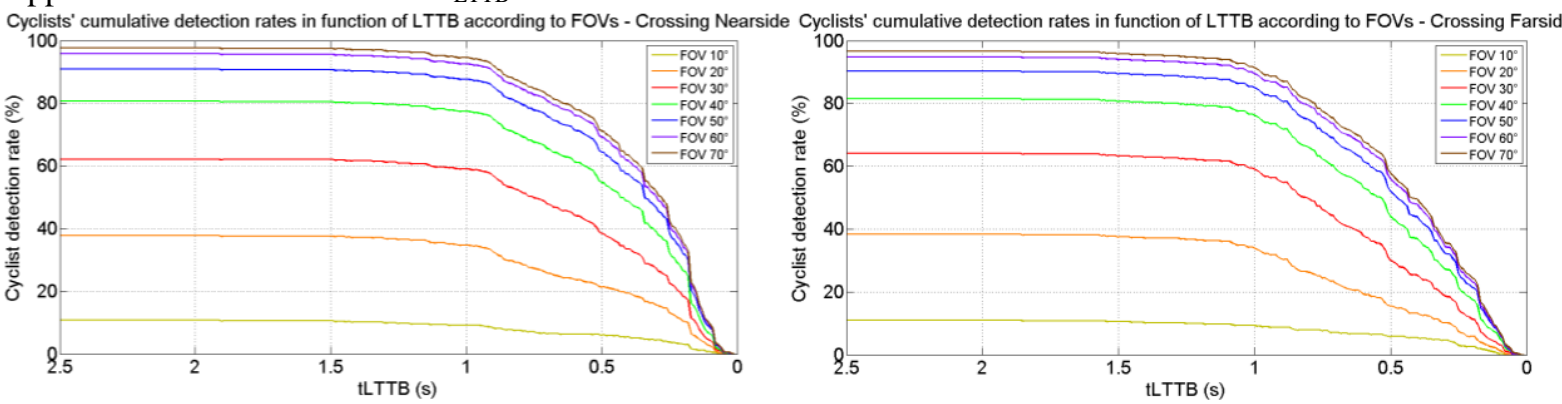

Cyclists' cumulative detection rates in function of LTTB according to FOVs - Longitudinal

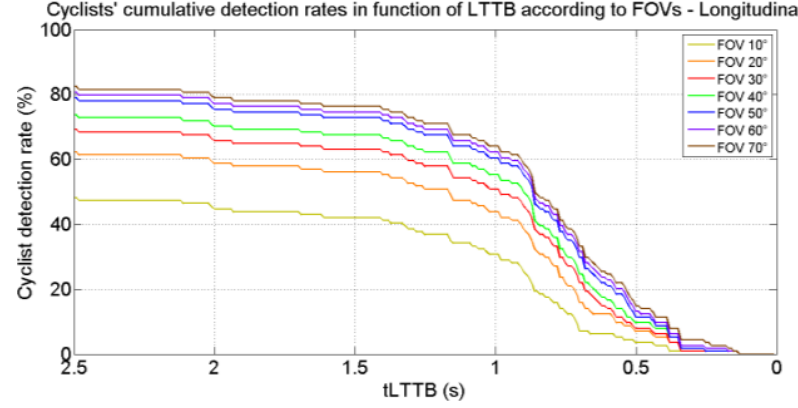




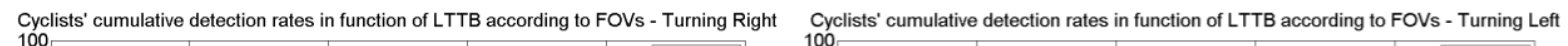
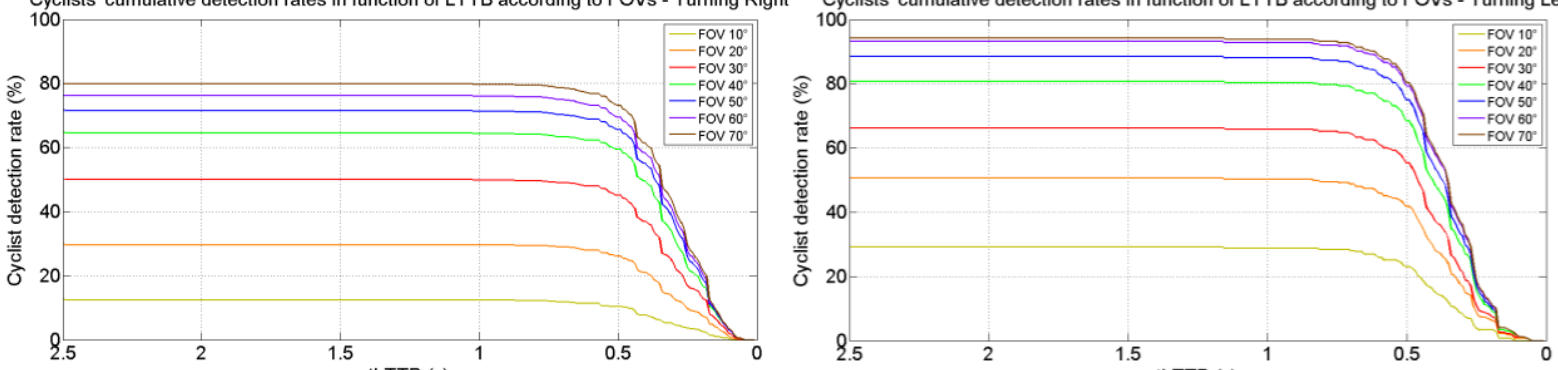

ILTTB (s)

$\operatorname{tLTTB}(\mathrm{s})$ 